\title{
A NOTE ON A FUNCTIONAL INEQUALITY
}

\author{
H. E. GOLLWITZER
}

In this paper we will consider the functional inequalities

$$
\begin{aligned}
& u(t) \leqq f(t)+g(t) G^{-1}\left(\int_{a}^{t} G(u(s)) h(s) d s\right) \quad a \leqq x \leqq t \leqq b, \\
& u(t) \geqq u(x)-g(t) G^{-1}\left(\int_{x}^{t} G(u(s)) h(s) d s\right)
\end{aligned}
$$

where the functions $u, f, g$ and $h$ are nonnegative and continuous on the interval $[a, b]$. The function $G(u)$ is continuous and strictly increasing for $u \geqq 0, G(0)=0, \lim _{u \rightarrow \infty} G(u)=\infty$ and $G^{-1}$ denotes the inverse function of $G$. If $G(u)=u$, we have the well-known Gronwall inequality and a case similar to the Langenhop inequality [3]. If $G(u)=u^{p}, p \geqq 1$, then Willett [4] has studied (1) in connection with a singular perturbation problem. Our purpose here is to obtain new estimates for $u(t)$ if $G$ is a convex or concave function. Before giving the main results, we will state two important preliminary lemmas.

LEMma 1. Let $u(t), f(t), g(t)$ and $h(t)$ be nonnegative, continuous functions on the interval $[a, b]$; and

$$
u(t) \leqq f(t)+g(t) \int_{a}^{t} u(s) h(s) d s, \quad a \leqq t \leqq b .
$$

Then

$$
\int_{a}^{t} u(s) h(s) d s \leqq \int_{a}^{t} h(s) f(s) \exp \left(\int_{8}^{t} h(x) g(x) d x\right) d s, a \leqq t \leqq b .
$$

A proof of this form of Gronwall's inequality can be found in [1], [2] or [5]. An estimate for $u$ is obtained by substituting (4) back into (3).

LEMMA 2. Let $u(t), v(t), h(t)$ and $k(t)$ be nonnegative, continuous functions on the interval $[a, b]$; and

$$
u(t) \geqq v(x)-k(t) \int_{x}^{t} v(s) h(s) d s, \quad a \leqq x \leqq t \leqq b .
$$

Then

$$
u(t) \geqq v(x) \exp \left(-k(t) \int_{x}^{t} h(s) d s\right), \quad a \leqq x \leqq t \leqq b .
$$

Received by the editors January 20, 1969. 


\section{Proof of Lemma 2. Let}

$$
\psi(x)=\left(u(t)+k(t) \int_{x}^{t} v(s) h(s) d s\right), \quad a \leqq x \leqq t .
$$

From (7) we have

$$
\psi^{\prime}(x)=-v(x) h(x) k(t) \geqq-\psi(x) h(x) k(t), \quad a \leqq x \leqq t,
$$

since $\psi(x) \geqq v(x)$. The derivative $\psi^{\prime}(x)$ at the end points is taken to be the limit from the interior of $[a, t]$. Then, using the integrating factor

$$
\mu(x)=\exp \left(-k(t) \int_{x}^{t} h(s) d s\right)
$$

we have $(\mu \psi)^{\prime}(x) \geqq 0$ and so $(\mu \psi)(t) \geqq(\mu \psi)(x)$ on $[a, t]$. Now $\psi(x) \geqq v(x)$ and $\psi(t)=u(t)$ (from (7)) and so we have the result given in (6). This result is best possible in the sense that if equality holds in (5) on $[a, t]$, then equality holds in (6) on $[a, t]$.

Q.E.D.

REMARK. This lemma is similar to a special case of the Langenhop inequality [3], and an estimate for $u$ which is independent of $x$ is obtained by setting $x=a$.

A continuous function $k(t)$ defined on some interval $I$ is said to be convex if $k(\alpha x+\beta y) \leqq \alpha k(x)+\beta k(y), x, y \in I, \alpha, \beta \geqq 0, \alpha+\beta=1 ; k(t)$ is said to be concave if $-k(t)$ is convex. The previous inequality is a special case of Jensen's inequality for convex functions. $G(u)$ is said to be submultiplicative if $G(u v) \leqq G(u) G(v), u, v \geqq 0$.

The main results of the paper are given in Theorem 1 and Theorem 2. The appropriate hypotheses for the Lebesgue version of the results given here are not difficult to supply, and we leave them for the reader to fill in where needed.

THEOREM 1. Let $u(t), f(t), g(t)$ and $h(t)$ be nonnegative, continuous functions on the interval $[a, b] ; G(u)$ be a continuous, strictly increasing, convex and submultiplicative function for $u \geqq 0 ; G(0)=0$, $\lim _{u \rightarrow \infty} G(u)=\infty ; \alpha(t), \beta(t)$ be continuous functions on $[a, b] ; \alpha(t)$, $\beta(t)>0, \alpha(t)+\beta(t)=1$; and

$$
u(t) \leqq f(t)+g(t) G^{-1}\left(\int_{a}^{t} G(u(s)) h(s) d s\right), \quad a \leqq t \leqq b .
$$

Then

$$
\text { (8) } \begin{aligned}
& \int_{a}^{t} G(u(s)) h(s) d s \\
& \leqq \int_{a}^{t} \alpha(s) G\left(f(s) \alpha(s)^{-1}\right) h(s) \exp \left(\int_{s}^{t} \beta(x) G\left(g(x) \beta(x)^{-1}\right) h(x) d x\right) d s .
\end{aligned}
$$


Furthermore, if

$$
u(t) \geqq u(x)-g(t) G^{-1}\left(\int_{x}^{t} G(u(s)) h(s) d s\right), \quad a \leqq x \leqq t \leqq b,
$$

then

(9) $u(t) \geqq \alpha(t) G^{-1}\left(\alpha(t)^{-1} G(u(x)) \exp \left(-\beta(t) G\left(g(t) \beta(t)^{-1}\right) \int_{x}^{t} h(s) d s\right)\right)$,

$$
a \leqq x \leqq t \leqq b .
$$

An estimate for $u(t)$ is obtained by substituting (8) back into (1).

Corollary 1. If $G(u)=u^{p}, 1 \leqq p<\infty$, then

$$
\int_{a}^{t} u(s)^{p} h(s) d s \leqq \int_{a}^{t} \alpha(s)^{1-p} f(s)^{p} h(s) \exp \left(\int_{s}^{t} \beta(x)^{1-p} g(x)^{p} h(x) d x\right) d s,
$$

$$
\begin{aligned}
u(t) \geqq \alpha(t)^{1-1 / p} u(x) \exp \left(\frac{-\beta(t)^{1-p}}{p} g(t)^{p} \int_{x}^{t} h(s) d s\right) & \\
& a \leqq x \leqq t \leqq b .
\end{aligned}
$$

In order to compare our estimate with that given by Willett [4], we take $g(t) \equiv 1, f(t) \equiv C, \alpha=\beta=\frac{1}{2}$ and obtain, from Corollary 1 ,

$$
u(t) \leqq C\left[1+\left(\exp \left(2^{p-1} \int_{a}^{t} h(s) d s\right)-1\right)^{1 / p}\right], \quad t \geqq 0 .
$$

By taking $p=2$ and $h(t) \equiv 1$ we have

$$
u(t) \leqq C\left[\exp (-t)+(1-\exp (-2 t))^{1 / 2}\right] \exp (t),
$$

and from Willett's estimate we obtain

$$
u(t) \leqq C\left[1+(1-\exp (-t))^{1 / 2}\right] \exp (t) .
$$

The estimate given in (11) is definitely sharper for large $t$, while for small values of $t$ the estimate given in (12) is sharper. Thus the two estimates are, in general, not comparable.

The left member of (8) is independent of $\alpha(t)$. It is unknown whether or not there is an optimum function $\alpha(t)$ which minimizes the right member of (8) for any reasonable class of functional parameters $f, g, h$ and $G$. We also note that if $0<g(t)<1$, then the submultiplicative hypothesis on $G$ can be omitted in Theorem 1 .

Proof of Theorem 1. Let $\alpha(t), \beta(t)>0, \alpha(t)+\beta(t)=1$. Then 
(1) $u(t) \leqq \alpha(t)\left(f(t) \alpha(t)^{-1}\right)+\beta(t)\left(g(t) \beta(t)^{-1}\right) G^{-1}\left(\int_{a}^{t} G(u(s)) h(s) d s\right)$.

Since $G$ is convex, submultiplicative and monotonic,

$$
\begin{array}{r}
G(u(t)) \leqq \alpha(t) G\left(f(t) \alpha(t)^{-1}\right)+\beta(t) G\left(g(t) \beta(t)^{-1}\right) \int_{a}^{t} G(u(s)) h(s) d s, \\
a \leqq t \leqq b .
\end{array}
$$

The estimate given in (8) follows from Lemma 1.

From (2),

$$
\begin{array}{r}
u(x) \leqq \alpha(t)\left(u(t) \alpha(t)^{-1}\right)+\beta(t) g(t) \beta(t)^{-1} G^{-1}\left(\int_{x}^{t} G(u(s)) h(s) d s\right), \\
a \leqq x \leqq t \leqq b .
\end{array}
$$

Since $G$ is convex, submultiplicative and monotonic,

$$
\alpha(t) G\left(u(t) \alpha(t)^{-1}\right) \geqq G(u(x))-\beta(t) G\left(g(t) \beta(t)^{-1}\right) \int_{x}^{t} G(u(s)) h(s) d s,
$$

and the result given in (9) follows from Lemma 2.

If $G$ is concave, the previous techniques are clearly not applicable. The following theorem gives partial results in this case.

THEOREM 2. Let $u(t), h(t)$ be nonnegative, continuous functions on the interval $[a, b] ; G(u)$ be a continuous, concave function for $u \geqq 0$, and continuously differentiable for $u>0 ; G^{\prime}(u)>0$ for $u>0, G(0)=0$, $\lim _{u \rightarrow \infty} G(u)=\infty ; C \geqq 0$ a constant; and

$$
u(t) \leqq C+G^{-1}\left(\int_{a}^{t} G(u(s)) h(s) d s\right), \quad a \leqq t \leqq b .
$$

Then

$$
u(t) \leqq G^{-1}\left(G(C) \exp \left(\int_{a}^{t} h(s) d s\right)\right), \quad a \leqq t \leqq b
$$

Furthermore, if

$$
u(t) \geqq u(x)-G^{-1}\left(\int_{x}^{t} G(u(s)) h(s) d s\right), \quad a \leqq x \leqq t \leqq b,
$$

then

$$
u(t) \geqq G^{-1}\left(G(u(x)) \exp \left(-\int_{x}^{t} h(s) d s\right)\right), \quad a \leqq x \leqq t \leqq b
$$


Corollary 2. If $G(u)=u^{p}, 0 \leqq p \leqq 1$, then

$$
u(t) \leqq C \exp \left(p^{-1} \int_{a}^{t} h(s) d s\right), \quad a \leqq t \leqq b
$$

and

$$
u(t) \geqq u(x) \exp \left(-p^{-1} \int_{x}^{t} h(s) d s\right), \quad a \leqq x \leqq t \leqq b .
$$

Proof of Theorem 2. It is sufficient to assume that $C$ is positive, since a standard limiting argument can be used to treat the remaining case. Consider (13) and define $\psi(t)$ as

$$
\psi(t)=C+G^{-1}\left(\alpha+\int_{a}^{t} G(u(s)) h(s) d s\right), \quad \alpha>0, \quad a \leqq t \leqq b .
$$

We note that $\psi(t)$ majorizes the right member of (13), and hence $\psi(t) \geqq u(t)$. Since $G(u)$ is concave, the derivative $G^{\prime}(u)$ is nonincreasing for $u>0$. Since $\psi(t)-C>0$ (here is where we use the constant $\alpha$ ),

$$
G^{\prime}(\psi(s)) \leqq G^{\prime}(\psi(s)-C), \quad a \leqq t \leqq b .
$$

Furthermore, by the fundamental theorem of integral calculus,

(21) $\ln G(\psi(t))-\ln G\left(C+G^{-1}(\alpha)\right)=\int_{a}^{t} G^{\prime}(\psi(s)) G(\psi(s))^{-1} \psi^{\prime}(s) d s$, where

$$
\psi^{\prime}(s)=G(u(s)) h(s)\left\{G^{\prime}(\psi(s)-C)\right\}^{-1} .
$$

Since $\psi(t) \geqq u(t)$ and $(20)$ holds, the integrand in (21) is majorized by $h(s)$. Hence,

$$
\ln \left(G(\psi(t)) / G\left(C+G^{-1}(\alpha)\right)\right) \leqq \int_{a}^{t} h(s) d s, \quad a \leqq t \leqq b,
$$

or

$$
G(u(t)) \leqq G(C) \exp \left(\int_{a}^{t} h(s) d s\right), \quad a \leqq t \leqq b,
$$

since the continuity of $G$ permits us to let $\alpha$ approach zero. Thus the first assertion has been proven.

Consider (15) and define $\phi(x)$ as

$$
\phi(x)=u(t)+G^{-1}\left(\int_{x}^{t} G(u(\tau)) h(\tau) d \tau\right), \quad a \leqq x \leqq t .
$$


We note that $\phi(x) \geqq u(x)$. Assume that $u(t)$ is positive on $[a, b]$. Since $G$ is concave and continuously differentiable, we can use the techniques given in the first part of the proof to show that

$$
\ln G(\phi(t))-\ln G(\phi(x)) \geqq-\int_{x}^{t} h(s) d s, \quad a \leqq x \leqq t \leqq b,
$$

and hence

$$
G(u(t)) \geqq G(u(x)) \exp \left(-\int_{x}^{t} h(s) d s\right), \quad a \leqq x \leqq t \leqq b .
$$

The estimate given in (16) is now clear. If $u(t)$ is not positive on $[a, b]$, we can replace $u(t)$ by $\{u(t)+\epsilon\}$ in (15), $\epsilon>0$, and then let $\epsilon \rightarrow 0$ in (24) to complete the theorem.

Q.E.D.

Acknowledgment. The author wishes to thank the referee for suggesting several improvements in the paper, particularly the final version of Lemma 2.

\section{REFERENCES}

1. S. C. Chu and F. T. Metcalf, On Gronwall's inequality, Proc. Amer. Math. Soc. 18(1967), 439-440.

2. G. S. Jones, Fundamental inequalities for discrete and discontinuous functional equations, J. Soc. Indust. Appl. Math. 12(1964), 43-57.

3. C. E. Langenhop, Bounds on the norm of a solution of a general differential equation, Proc. Amer. Math. Soc. 11(1960), 795-799.

4. D. Willett, Nonlinear vector integral equations as contraction mappings, Arch. Rational Mech. Anal. 15 (1964), 79-86.

5. - A linear generalization of Gronwall's inequality, Proc. Amer. Math. Soc. 16 (1965), 774-778.

UNIVERSITY OF TENNESSEE 